\title{
LA CONSTITUCIÓN DE CÁDIZ Y NOSOTROS: REFLEXIONES EN TORNO A LOS MODELOS DE CONSTITUCIÓN
}

Francisca Pou Giménez*

\section{Los significados de Cádiz}

La convocatoria a Cortes, finalmente reunidas en la ciudad de Cádiz desde 1810, y la posterior aprobación -el 19 de marzo de 1812- del texto constitucional cuyo análisis nos congrega han sido consideradas un hito en la historia política y jurídica de muchos países. Así ha sido ciertamente en la historia de España y también en la historia de la mayoría de los Estados latinoamericanos -aunque, como ha señalado recientemente Roberto Breña, parece ser mucho mayor el lugar que Cádiz ha jugado en la reconstrucción de la historia política de países como México o Perú que en la de Venezuela o Argentina- ${ }^{1}$ La Constitución de 1812, celebrada por las callejuelas gaditanas al grito de "iviva la Pepa!" en recuerdo del día de su proclamación, en una ciudad sitiada, aislada, invadida por la enfermedad, en un contexto de dislocación total de los poderes, de invasión externa, de guerra civil, se convirtió en un momento histórico fundacional y casi mítico.

* Profesora investigadora de Derecho Constitucional, Departamento de Derecho, ITAM. Una versión anterior de este trabajo fue presentada en el seminario "La Constitución de Cádiz, el liberalismo español y sus proyecciones en América Latina”, celebrado en el ITAM el 21 de marzo de 2012. Agradezco a Eugenio Velasco Ibarra Argüelles su asistencia en esta investigación.

'Véase "Momento Gaditano", El País, 4 de febrero de 2012. Véase asimismo Roberto Breña (ed.), En el umbral de las revoluciones hispánicas. El bienio 1808-1810, 2010, México, El Colegio de México; y El primer liberalismo español y los procesos de emancipación de América, 1808-1824. Una revisión historiográfica del liberalismo hispánico, 2006, México, E1 Colegio de México. 
FRANCISCA POU GIMÉNEZ

La unanimidad respecto a la condición de hito histórico reposa sin duda en muchas bases. Cádiz fue, para empezar, la primera constitución hispana: con anterioridad a los hechos de 1808-1812 se vivía bajo "leyes fundamentales" del reino, y el Estatuto de Bayona era en realidad una carta otorgada. La vida bajo un texto llamado "constitución" es la vida que españoles y americanos hemos tenido desde entonces y esa vida empezó con Cádiz. La Constitución de Cádiz fue también el documento que dijo por primera vez, y tanto para los territorios españoles como para los americanos y los asiáticos, que la soberanía residía en la nación: ya no en el rey, aunque todavía tampoco en el pueblo -para eso se tendría que esperar, en España, hasta la Constitución de 1931-. ${ }^{2}$ La Constitución de 1812 erradicó además la condición de "súbdito", inauguró la de "ciudadano", definió la ciudadanía en términos que incluían a una considerable cantidad de personas adultas ${ }^{3}$ y proclamó en su artículo $1^{\circ}$ que la nación estaba compuesta por los españoles de los dos hemisferios. ${ }^{4}$

Cádiz estableció asimismo la división de poderes -y una división de poderes bastante rígida- con predominio de un Poder legislativo unicameral. El Legislativo, integrado por medio de un sistema de sufragio indirecto en varios grados, debía gobernar con un Ejecutivo monárquico, ciertamente, pero con poderes claramente subordinados a

${ }^{2}$ En México, el artículo $5^{\circ}$ del texto de Apatzingán (1814) sí estableció que "la soberanía reside originariamente en el pueblo". Este reconocimiento no se incluiría, sin embargo, en las constituciones que cobraron vigencia durante la primera mitad del siglo XIX. El "pueblo" regresó con la Constitución de 1857, que en su artículo 39 disponía que "la soberanía nacional reside esencial y originariamente en el pueblo". Para una panorámica general sobre los textos constitucionales mexicanos, véase Patricia Galeana (comp.), México y sus constituciones, 2003, México, Fondo de Cultura Económica, $2^{\mathrm{a}}$. ed.

${ }^{3}$ Según los artículos 18 a 22 de la Constitución de Cádiz, la calidad de ciudadano la ostentaban "aquellos españoles que por ambas líneas traen su origen de los dominios españoles de ambos hemisferios, y están avecindados en cualquier pueblo de los mismos dominios". Además, como destaca María del Refugio González Domínguez, la Constitución de Cádiz "reconoce esta misma calidad a los hijos legítimos de extranjeros que hubieran nacido en los dominios españoles y que no hubieran salido de ellos, siempre que tuvieran una industria útil; da opción para que los descendientes de las razas africanas obtengan dicha calidad por méritos y servicios a la patria", cfr. "Análisis jurídico de la Constitución política de Cádiz, 1812” en México y sus constituciones, op. cit., p. 31.

${ }^{4}$ Así lo disponía, a la letra, el artículo que abría la Constitución: "la Nación española es la reunión de todos los españoles de ambos hemisferios". 
DOSSIER

los de los representantes, a la vista de la regulación constitucional de figuras como el veto, la iniciativa legislativa, el sistema de refrendos de los actos del monarca o el peso de las Cortes en la conformación del Consejo de Estado. ${ }^{5}$ Cádiz creó también los tribunales de justicia -la primera versión del poder judicial tal y como lo conocemos ahora-; consagró la libertad de imprenta, declaró que el fin del Estado era proteger la libertad civil, la propiedad y los demás derechos legítimos de los individuos mediante leyes sabias y justas, previó la instrucción básica a cargo del Estado y declaró que la felicidad de la nación -la felicidad, ese ideal ilustrado- era el fin del gobierno. ${ }^{6}$

La unanimidad no se replica, sin embargo, cuando se trata de interpretar el alcance y las consecuencias de ese hito, da ocasión a un ejercicio saludable, necesario de algún modo para que el mito gaditano conserve su fecundidad.

Los historiadores y constitucionalistas latinoamericanos, por ejemplo, debaten qué tanto sentido tiene neo-reivindicar Cádiz como una de las fuentes importantes del constitucionalismo americano del siglo XIX. Todo el mundo reconoce la importancia trascendental que tuvo la convocatoria a Cortes en el nacimiento de una dinámica de articulación de identidad y acción política que resultó ser irreversible y que llevó en pocos años a la independencia de muchas naciones americanas, pues la convocatoria a Cortes y el ejercicio que fue necesario para seleccionar quién viajaría a España permitió a las diferentes partes de la América todavía española entenderse por primera vez como sujetos frente a la península y otras partes del imperio; les permitió darse cuenta del peso

${ }^{5}$ Algunas de las disposiciones significativas en este sentido son, por ejemplo, la atribución a los diputados de la facultad de iniciativa legislativa contemplada en el artículo 132; las importantes restricciones a la autoridad real incluidas en el artículo 172 -como la imposibilidad de convocar Cortes o ausentarse del reino sin su consentimiento, o la de enajenar, ceder o renunciar a sus prerrogativas o a cualquier parte del territorio español-; la regulación del veto real en el artículo 144; la previsión en el artículo 347 según la cual "ningún pago se admitirá en cuenta al tesorero general, si no se hiciere en virtud de decreto del Rey, refrendado por el secretario del despacho de Hacienda, en el que se expresen el gasto a que se destina su importe y el decreto de las Cortes con que éste se autoriza"; o la conformación del Consejo de Estado, tan detalladamente prevista en los artículos 231 a 241.

${ }^{6}$ La libertad de imprenta se reconocía en el artículo 371; el artículo $4^{\circ}$ establecía las obligaciones de la nación; la instrucción escolar se preveía en los artículos 366 y siguientes; el objeto del gobierno, en el artículo 13. 
FRANCISCA POU GIMÉNEZ

económico que tenían para la monarquía -se dice que los cambios radicales en términos de fiscalidad introducidos por el texto gaditano, especialmente los que concernían a América, estuvieron entre las causas centrales del gran rechazo que produjo en Fernando VII- ${ }^{7}$ y les permitió darse cuenta de que lo que expresaran tendría importancia en el desarrollo de los acontecimientos. ${ }^{8}$ Pero ya no hay tanto acuerdo a la hora de aquilatar, por ejemplo, la huella de Cádiz en las constituciones de la América independiente. Una tesis muy difundida tradicionalmente entre los constitucionalistas señala que las primeras constituciones americanas fueron escritas "contra Cádiz", un texto que los movimientos de independencia habrían rechazado al no ser capaz, entre otras cosas, de acoger la descentralización política que hubiera sido necesaria para que los americanos cupieran en España; ello motivó, se dice, el giro hacia el constitucionalismo de los Estados Unidos, que sí ofrecía herramientas para hacer constituciones con régimen federal. ${ }^{9}$ Más recientemente, sin embargo, se subraya presencia de la huella gaditana en aspectos como la división horizontal de los poderes -las primeras constituciones latinoamericanas eran más mayoritaristas que la estadounidense-, ${ }^{10}$ la definición de la ciudadanía o -como subrayaré en un momento-en las características de las constituciones mexicanas vistas como textos, como arquitecturas legales que encapsulan modos de entender cómo debe ser pensada y redactada una constitución.

${ }^{7}$ Véase Manuel Chust, “La Constitución de 1812 y América”, El País, 21 de abril de 2012.

${ }^{8}$ Mirian Galante, "La prevención frente a depotismo. El primer liberalismo en Nueva España y México, 1808-1834”, Mexican Studies/Estudios Mexicanos, (Summer 2008), vol. 24, núm. 2, University of California Press, pp. 421-53. Asimismo, véase Manuel Chust, "La Constitución de 1812 y América", op. cit.

${ }^{9}$ Véase Manuel Chust e Ivana Frasquet, "Los orígenes del republicanismo en México, 1810-1824”, Mexican Studies/Estudios Mexicanos, (Summer 2008), vol. 24, núm. 2, University of California Press, p. 368. Como estos autores señalan, "Nueva España era demasiado valiosa para las rentas reales como para dejarla escapar en un plano autonomista que tenía cada vez más tintes federalistas. Y, ¿qué país representaba el ejemplo federal por excelencia? Estados Unidos de Norteamérica... .una ex-colonia y ahora un Estado republicano, un estado donde el federalismo no sólo se practicaba sino que se teorizaba, un estado que, como decían los diputados mexicanos en el Congreso de 1823, se había federalizado desde la disgregación para unirse, y no al contrario".

${ }^{10}$ Roberto Gargarella ha destacado recientemente este punto. Véase "Una maquinaria exhausta. Constitucionalismo y alienación legal en América", Isonomía. Revista de Teoría y Filosofía del Derecho, octubre 2010, núm.33, pp. 14-6. 
Los historiadores y constitucionalistas de España, por su parte, discuten la relevancia de Cádiz como modelo exitoso o fallido de integración histórica. Cádiz es reconocida como el nacimiento oficial del liberalismo en España, esa semilla que la delicada pero intensa ilustración española (Macanaz, Feijoo, Jovellanos, Floridablanca) pudo introducir por primera vez en el mundo del derecho, ${ }^{11}$ pero también como un texto centralista -afrancesado en ese sentido- que al tiempo que eliminaba los privilegios estamentales y establecía un régimen fiscal único para todos, imponía un Estado unitario que perpetuaría problemas iniciados con la sustitución del pluralismo jurídico de los Austrias por el uniformismo borbónico a principios del siglo XVIII y que sólo podrían empezar a resolverse en la España democrática de finales del siglo XX. O como un texto que, para marcar distancias del invasor francés y granjearse el apoyo del clero, establecía una monarquía católica oficial -recordemos que el artículo 12 decía que "la religión de la Nación española es y será perpetuamente la católica, apostólica, romana, única verdadera. La nación la protege por leyes sabias y justas y prohíbe el ejercicio de cualquier otra"-, lo cual acabó determinando fuertemente el modo en que se desplegó la historia política y social española en los dos siglos siguientes.

Cádiz es, en breve, un momento histórico apasionante desde el cual mirar procesos de definición de comunidades políticas que todavía están inconclusos y puede ser analizado a muchos niveles. En las páginas que siguen quiero reflexionar brevemente sobre el texto doceañista desde una perspectiva que, para los estudiosos de la teoría constitucional contemporánea, es sugestiva: la del constitucionalismo como técnica, la perspectiva de los modelos de constitución: la perspectiva centrada en estudiar las distintas aproximaciones que uno puede tomar a la hora de pensar cómo debe ser escrito y estructurado un texto constitucional y cuál es la relación que debe tratar de construirse entre texto constitucional y estrategias de cambio social. ${ }^{12}$

${ }^{11}$ Véase José María Lassalle, "España quiere ser moderna e ilustrada”, El País, 19 de marzo de 2012.

${ }^{12}$ Sobre este último punto, véase María Paula Saffon y Mauricio García Villegas, "Derechos sociales y activismo judicial. La dimensión fáctica del activismo judicial en derechos sociales", Revista Estudios Socio-Jurídicos, 2011, vol. 13, núm. 1, pp. 79-81. 
FRANCISCA POU GIMÉNEZ

Comparar nuestra actual Constitución con la de Cádiz nos permite detectar lo mucho que han cambiado las cosas, pero también identificar líneas de continuidad sorprendentes con ese texto tan antiguo. Me parece interesante como parte de un ejercicio más amplio encaminado a pensar si, paradójicamente, algunas de las características de la Constitución mexicana actual como texto, como arquitectura -con el poso de Cádiz pero, por supuesto, no necesariamente a causa de ese poso-no podían en realidad ser más obstáculo que ayuda para empujar el tipo de proyecto colectivo emancipador que Cádiz - con independencia de las limitaciones finalmente reveladas por sus relecturas realistas- ha sabido evocar, durante doscientos años, en nuestro imaginario histórico y político.

\section{Cádiz, los modelos de constitución y el texto actual}

Aunque la vigencia del texto constitucional gaditano fue rápidamente suprimida por Fernando VII en 1814 y después sólo brevemente reinstaurada durante el llamado trienio liberal (de 1820 a 1823), en un momento en el que en América esa reinstauración ya no tenía un lugar,

106 Cádiz fue un texto constitucional tremendamente influyente. Los investigadores que miden los movimientos de migración, importación y exportación de textos y diseños constitucionales la sitúan -junto con la constitución belga de 1831- entre las más copiadas del mundo, con una influencia particular sobre la portuguesa de 1830, la italiana de 1871 e incluso la de la Rusia zarista. ${ }^{13}$

Desde la perspectiva de la teoría y la práctica de los diseños constitucionales, sin embargo, las cosas han cambiado mucho en doscientos años. Identificar y comentar algunas de las características de la Constitución gaditana como texto nos ayuda a entender e ilustrar hasta qué punto es así, pero también a iluminar singularidades de la Constitución mexicana actual frente a la mayoría de sus contemporáneas.

${ }^{13}$ Para un rastreo de los textos constitucionales europeos más influyentes durante el siglo XIX, véase Zachary Elkins, , "Diffusion and the Constitutionalization of Europe", Comparative Political Studies, 2010, núm.43, pp. 969-99. 
Los rasgos que brevemente voy a subrayar son tres: Cádiz como una constitución de parte orgánica (en oposición a una constitución de parte dogmática); como constitución de detalle (en oposición a una constitución de principios o abstracta); y como una constitución aspiracional (en oposición a una constitución preservadora o conservadora, focalizada en el mantenimiento del status quo).

\section{Una Constitución de parte orgánica}

Cádiz es, sin duda, lo que propongo llamar una constitución "de parte orgánica”. En la era del constitucionalismo de los derechos -nuestra época- nos parece que la gran extensión de las partes dogmáticas de las constituciones es algo que siempre ha estado ahí. Pero Cádiz nos recuerda que las primeras constituciones eran documentos esencialmente preocupados por estructurar los poderes del Estado y por definir la ciudadanía, con declaraciones de derechos más bien exiguas. Aunque el famoso artículo 16 de la Declaración francesa de Derechos del Hombre y del Ciudadano dejó dicho para la posteridad que allí donde el poder no está dividido y los derechos asegurados " $n$ 'a point de constitution", la incorporación textual explícita de los derechos no se consideraba un elemento estructural necesario para la existencia de esa constitución "conceptual".

La mencionada Declaración de 1789 fue de hecho aprobada por la Asamblea nacional constituyente como algo distinto a una constitución, y la Constitución de 1791 la incorporó en calidad de preámbulo. Las de 1793 o 1795 contenían por su parte referencias muy sintéticas a los fines del Estado o a titularidades ciudadanas concretas. De igual forma, la Constitución federal de los Estados Unidos fue adoptada en 1789 y en 1791 se le añadieron las primeras diez enmiendas, entendidas en algún sentido como un cuerpo aparte -el llamado Bill of Rights-; aunque el preámbulo de este documento presenta los artículos como cláusulas que, una vez ratificadas, "serían válid(a)s para todos los fines y propósitos como parte de la Constitución”, lo cierto es que esta adición se produjo en un momento temporal distinto y después 
FRANCISCA POU GIMÉNEZ

de una álgida discusión acerca de si su inclusión en un texto que ya se consideraba una "constitución" - entera y vigente- la perfeccionaría o acabaría poniéndola en peligro. ${ }^{14}$ La Constitución de Cádiz, por su parte, siendo un extenso texto de 384 artículos, incorporaba muy pocas cláusulas que ahora consideraríamos "cláusulas sobre derechos": el artículo $4^{\circ}$, que como he señalado establecía que "la Nación está obligada a conservar y proteger por leyes sabias y justas la libertad civil, la propiedad y los demás derechos legítimos de todos los individuos que la componen", las innovadoras previsiones en materia de instrucción pública previstas en los artículos 366 a 371, o la libertad de imprenta reconocida en el artículo 371.

Ello no significa, claro, que los derechos fundamentales no fueran importantes para el constituyente gaditano y el resto de constituyentes inaugurales. Claramente lo eran. Estas constituciones tempranas eran el precipitado de teorías filosóficas y políticas contractualistas que desde hacía por lo menos cien años venían poniendo la garantía de los derechos naturales de los individuos en la base justificativa del Estado y, por tanto, de la constitución. Lo que significa es que el primer constitucionalismo moderno estaba construido sobre una concepción constitucional completamente distinta de la que ahora predomina, ${ }^{15}$ una concepción mecánica, procedimental, política, de la constitución, en oposición a la concepción normativa, sustantiva, jurídica de la constitución que singulariza nuestro tiempo. ${ }^{16}$ Dicha concepción asume que la clave para la preservación de los derechos es el modo de estructurar la autoridad pública y el ejercicio de sus facultades, en contraposición a una que asume que lo realmente esencial es enfatizar los principios y fines que estas autoridades deben perseguir en el desplie-

${ }^{14}$ En El Federalista núm. 84, Alexander Hamilton argumentaba, por ejemplo, que la Constitución era en sí misma una carta de derechos, que su ratificación en modo alguno debía interpretarse como algo que hubiera restringido la extensión plena natural de los derechos de las personas y que, por tanto, las menciones específicas a derechos en un texto fundamental eran totalmente innecesarias.

${ }^{15}$ Véase el trazo inicial de la capital distinción entre "concepto" y "concepción", parte ahora del utillaje analítico cotidiano de los juristas, en Ronald Dworkin, Los derechos en serio, 1989, Barcelona, Ariel, cap. 5.

${ }^{16}$ Véase Josep Aguiló Regla, La Constitución del Estado constitucional, 2004, Bogotá y Lima, Temis-Palestra, pp. 64-104. 
DOSSIER

gue cotidiano de sus atribuciones. ${ }^{17}$ Toda constitución, ha subrayado Josep Aguiló, tiene dos dimensiones: la constitutiva, que se concreta en la parte orgánica (establecimiento de las formas de acción política y jurídica) y refleja o exige una teoría de la autoridad; y la regulativa, la parte dogmática, que establece los fines, objetivos y límites de la acción estatal, asociada con una teoría de la justicia. ${ }^{18}$ Pero el énfasis en una u otra señala el sentido de la evolución histórica: mientras que el énfasis en la parte orgánica es característico del Estado legislativo de derecho, el énfasis en la parte dogmática es característico del Estado constitucional de derecho -el constitucionalismo actual-.${ }^{19}$ Las primeras constituciones, como nos recuerda el texto gaditano o discusiones estadounidenses recogidas en El Federalista, en lo que realmente le tenían fe era en la capacidad de estructurar los poderes de modo tal que, con independencia de sus intenciones, sus ocupantes vieran canalizadas sus acciones dentro de una ingeniería institucional cuyo resultado necesario fuera el respeto de la libertad.

Destacar esto nos ayuda a entender lo mucho que nuestras ideas han cambiado sobre el constitucionalismo como técnica, lo mucho que ha variado el entendimiento de lo que creemos importante que una constitución haga para ser una buena constitución. Las constituciones deben tener una parte orgánica, en efecto, pero lo que ahora nos parece verdaderamente crucial es que incorporen estándares sustantivos de actuación: el constitucionalismo de los derechos. También nos ayuda a detectar que el texto constitucional mexicano actual, curiosamente, ha evolucionado por acumulación, no por sustitución. Con posterioridad a Cádiz,

${ }^{17}$ Ibid., p. 48.

${ }^{18}$ Ibid., p. 44.

${ }^{19}$ Ibid., pp. 46-50, 57-9. Explica Aguiló: "La idea del reconocimiento de valores supone que estos son 'anteriores' a las formas de acción política creadas por la Constitución y la idea de reconocimiento de fines, supone que éstos son 'externos' las formas de acción política creadas por la Constitución. Esto los convierte en un elemento de crítica y valoración de la conducta política efectiva realizada según las formas de acción política creadas por la Constitución" (p. 46). Sin embargo, sobre esa base todavía cabe distinguir entre las concepciones que creen que la efectividad de los valores y fines que centran la concepción contemporánea de las constituciones dependen centralmente de un buen diseño de las formas de acción jurídica y política y las que creen que la clave es traducir esos valores en deberes, afirmando la dimensión regulativa de la Constitución (p. 48). 
México se incorporó paulatinamente al constitucionalismo de los derechos -y en muchos puntos de manera pionera, pues la Constitución de 1917 es reconocida como la primera que incorporó derechos sociales, dos años antes de que lo hiciera la de Weimar-;20 el capítulo más reciente en la progresión es la incorporación, tras la reforma constitucional de junio de 2011, de los derechos humanos consagrados en los tratados como derechos con rango constitucional.

Nada de ello ha llevado, sin embargo, a eliminar el énfasis y la extraordinaria cantidad de disposiciones que la Constitución mexicana actual sigue dedicando al establecimiento y regulación de las autoridades públicas: sigue habiendo un altísimo número de reglas detalladas de estructuración orgánica y procedimental -tanto sobre los poderes clásicos como sobre los nuevos organismos autónomos o desconcentrados que han venido a complementarlos- que en otros países del mundo estarían, sin duda, en normas de rango infra-legal. Añadido a lo que a continuación referiremos, ello plantea complejidades importantes a la hora de interpretar y aplicar la constitución.

\section{Una Constitución de detalle}

La persistencia de una parte orgánica extraordinariamente extensa en el tiempo del constitucionalismo normativo de los derechos se liga en el texto constitucional vigente con un segundo rasgo que también marca una línea de continuidad con la Constitución de Cádiz: el ser un ejemplo de libro del modelo de constitución "de detalle", en oposición a lo que se ha llamado una constitución "de principios", abstracta, por decirlo utilizando aquí una distinción de Ronald Dworkin, ${ }^{21}$ fructíferamente adoptada por Víctor Ferreres para el análisis de varios aspectos de teoría constitucional. ${ }^{22}$

${ }^{20}$ Véase, por ejemplo, Jorge Carpizo Mac Gregor, La Constitución Mexicana de 1917, 2004, México, UNAM, pp. 175-6; Armando Hernández Cruz, Los derechos económicos, sociales y culturales y su justiciabilidad en el derecho mexicano, 2010, México, IIJ, UNAM, p. 1 y Memoria del Coloquio sobre Derechos Sociales, 2006, México, Suprema Corte de Justicia de la Nación.

${ }^{21}$ Ronald Dworkin, Life's Dominion, 1993, New York, Alfred Knopf.

${ }^{22}$ Víctor Ferreres Comella, Justicia constitucional y democracia, 1997, Madrid, Centro de Estudios Políticos y Constitucionales. 
DOSSIER

La Constitución de Cádiz tiene 384 artículos y prevé con un grado inmenso de detalle una notable cantidad de situaciones, como por ejemplo las palabras textuales que debían pronunciar los diputados al asumir el cargo ${ }^{23}$ o el Rey al asumir el trono, ${ }^{24}$ o el modo de determinar la dotación correspondiente a cada uno de los miembros de la familia real. ${ }^{25}$ Solamente la regulación del sistema de elección de diputados mediante la constitución de juntas electorales de parroquia, de partido y de provincia -sin incluir en el cálculo las reglas sobre celebración de cortes, facultades del legislativo y procedimiento legislativo-ocupa en el texto gaditano 68 artículos. ${ }^{26}$ La acentuación de este rasgo en el texto constitucional de 1917 y sus sucesivas reformas son por todos conocidas. La constitución mexicana tiene 136 artículos, pero algunos de ellos son casi imposibles de leer en una sola vez. El artículo 27 -sobre el derecho de propiedad- tiene 3,419 palabras (18,055 caracteres, sin espacios); el artículo 123 -“del trabajo y la previsión social”tiene 3,700 (19,947 caracteres, sin espacios); el 122 -con las bases del régimen jurídico del Distrito Federal- tiene 3,159 (17,156 caracteres, sin espacios).

${ }^{23}$ El artículo 117 disponía al respecto: "En todos los años el día 25 de febrero se celebrará la última junta preparatoria, en la que se hará por todos los diputados, poniendo la mano sobre los Santos Evangelios, el juramento siguiente: ¿Juráis defender y conservar la religión católica, apostólica, romana, sin admitir otra alguna en el reino? -R. Sí juro. ¿Juráis guardar y hacer guardar religiosamente la Constitución política de la Monarquía española, sancionada por las Cortes generales y extraordinarias de la Nación en el año de mil ochocientos y doce? -R. Sí juro. ¿Juráis haberos bien y fielmente en el encargo que la Nación os ha encomendado, mirando en todo por el bien y prosperidad de la misma Nación? -R. Sí juro. Si así lo hiciereis, Dios os lo premie; y si no, os lo demande.

${ }^{24}$ El artículo 173 disponía: "El Rey en su advenimiento al Trono, y si fuere menor, cuando entre a gobernar el reino, prestará juramento ante las Cortes bajo la fórmula siguiente: «N. (aquí su nombre) por la gracia de Dios y la Constitución de la Monarquía española, Rey de las Españas; juro por Dios y por los Santos Evangelios que defenderé y conservaré la religión católica, apostólica, romana, sin permitir otra alguna en el reino: que guardaré y haré guardar la Constitución política y leyes de la Monarquía española, no mirando en cuanto hiciere sino al bien y provecho de ella: que no enajenaré, cederé ni desmembraré parte alguna del reino: que no exigiré jamás cantidad alguna de frutos, dinero ni otra cosa, sino las que hubieren decretado las Cortes: que no tomaré jamás a nadie su propiedad y que respetaré sobre todo la libertad política de la Nación y la personal de cada individuo: y si en lo que he jurado, o parte de ello, lo contrario hiciere, no debo ser obedecido; antes aquello en que contraviniere, sea nulo y de ningún valor. Así Dios me ayude, y sea en mi defensa; y si no, me lo demande.»

${ }^{25}$ Estas previsiones se ubican en los artículos 213 a 221.

${ }^{26}$ La regulación del poder legislativo se extiende del artículo 35 al 167. 
FRANCISCA POU GIMÉNEZ

Es claro que no estamos hablando solamente de una cuestión de extensión expresiva, sino también y primordialmente, de grado de concreción de las cuestiones que la constitución se siente llamada a establecer: el artículo 41, por ejemplo, que incluye el grueso de la regulación sobre partidos políticos y autoridades electorales, determina en los distintos incisos del apartado A de la fracción III de cuántos minutos dispondrá el IFE en televisión y radio, cuántos minutos deberá distribuir a cada partido según se esté en campaña o precampaña y en qué horario (¡tarde-noche!) deberá concederlos. ${ }^{27}$

Con independencia de lo que la inclusión en las constituciones de "regulación de desarrollo" nos indique acerca de dinámicas empeñadas en blindar voluntades políticas frente al cambio legal y con independencia de las razones que puedan explicar su persistencia hoy día, me interesa subrayar ahora algunas de sus implicaciones más claras. Vivir bajo una constitución de detalle, en contraposición a una abstracta, implica vivir bajo una constitución con escasa adaptabilidad al futuro: entrar en mucho detalle implica tomar como relevantes propiedades y circunstancias que muy pronto pueden trucarse en otras distintas. La constitución carece, así, de lo que algunos teóricos llaman "resistencia", ${ }^{28}$ y ello introduce presiones para tener que reformarla muchas veces. En congruencia con esta previsión y a pesar de lo rígido de las previsiones sobre reforma, ${ }^{29}$ el texto de 1917 ha sufrido alrededor de 600 reformas, ${ }^{30} \sin$ disminución del ritmo en los últimos quince años, caracterizados por la ausencia de mayorías claras en el Congreso.

El detalle del texto y la dinámica de reforma constitucional continua, por él propiciados, se relacionan a mi juicio con varias realidades profundamente problemáticas. La dinámica de reforma constitucional

${ }^{27}$ Véanse, por favor, las muy extensas y detalladas disposiciones de la sección A del artículo 41 de la Constitución federal, incisos a), b), c), d), e) y f).

${ }^{28}$ Francisco Tomás y Valiente, "La resistencia constitucional y los valores", Doxa, Cuadernos de Filosofia del Derecho, núm. 15-6, 1994, pp. 635-50, y Aguiló Regla, op. cit., pp. 105-52.

${ }^{29} \mathrm{El}$ artículo 135 dispone que para reformarla es necesario obtener, en el Congreso de la Unión, una mayoría de las dos terceras partes de los presentes y la posterior aprobación por la mayoría de los Estados.

${ }^{30}$ Tomo las cifras del cálculo de Miguel Carbonell en el período 1917-2007: unas 600 reformas, agrupadas en casi 170 decretos de reforma. Véase "El futuro de la Constitución", Nexos, febrero de 2007. 
permanente permite a los poderes mayoritarios que las aprueban, por ejemplo, presentarse ante los ciudadanos como diligentes impulsores de normas benéficas, abriendo una vía de mantenimiento o construcción de legitimidad sin asumir costos inmediatos, pues proyectan para el futuro - para cuando los que estén en el congreso sean otros- la más complicada tarea de aprobar leyes y programas de política pública para su desarrollo. Al mismo tiempo, el cambio constitucional continuo no fuerza o no permite a los jueces constitucionales desarrollar prácticas de consistencia fuertes - pues su base decisoria, la Constitución, al seguir cambiando, introduce bases de diferencia relevante todo el tiempo-. Incluso gran parte de la reflexión académica acaba teniendo un alcance diluido por los efectos de una dinámica que, de tan antigua, ha acabado por "normalizarse", por volverse casi invisible.

Por otro lado, la coexistencia de masivo clausulado de detalle con algunas disposiciones abstractas - que también las hay, sobre todo desde la inclusión constitucional de los tratados en el 2011- dificulta la construcción de pautas interpretativas y aplicativas congruentes y muestra lo difícil de operar con la Constitución mexicana bajo la idea de la constitución "abierta" -que permita desarrollos constitucionales muy diferentes entre sí, al impulso de opciones políticas e ideológicas muy diversas, sin que desaparezca, no obstante, la idea de marco permanente identificable-.${ }^{31}$ Aunque lo que acostumbramos analizar son problemas derivados de la excesiva imprecisión de los textos constitucionales, el caso mexicano nos ayuda a ver que también la textura excesivamente precisa ("cerrada") y, en cualquier caso, la coexistencia en su contexto de estos dos estilos opuestos dificulta la construcción de una teoría interpretativa adecuada y plantea con ello problemas para optimizar su fuerza normativa ${ }^{32}$.

No es posible desarrollar aquí estas consideraciones. Baste con dejar dicho que, sin ninguna duda, analizar la relación entre la arquitectura

${ }^{31}$ Aguiló, op. cit., p. 131.

${ }^{32} \mathrm{Ibid}$., p. 132 y ss.; para un interesante análisis de las relaciones entre constitución abierta, desarrollo constitucional e imprecisión (o abstracción) constitucional, por un lado, y Constitución cerrada, aplicación de la constitución y precisión de la constitución, dentro de un marco más general de evaluación de las posibilidades de despliegue de su función regulativa. 
FRANCISCA POU GIMÉNEZ

textual de nuestra constitución y algunas de los rasgos notorios de nuestra dinámica política e institucional es importante y urgente si estamos interesados -como deberíamos-en impulsar dinámicas importantes de cambio social desde la Constitución.

\section{Una Constitución aspiracional}

Cádiz, es, finalmente, una constitución "aspiracional", que invoca la posibilidad de cambio social, en contraposición con las constituciones "preservadoras", preocupadas por el mantenimiento del statu quo. Como señala Mauricio García Villegas -el autor de la distinción anterior- las constituciones preservadoras suelen prosperar en contextos políticos y sociales que ya han conseguido garantizar las condiciones básicas de progreso social y estabilidad institucional, o donde una revolución política ha sentado las bases para tales cambios estructurales; el objetivo de estas constituciones es preservar tales condiciones: sus metas son minimalistas y sus contenidos reflejan un esfuerzo por conservar el presente. ${ }^{33}$ Las constituciones aspiracionales, en cambio, suelen ser halladas en contextos en los que existe una profunda insatisfacción por el presente y una fuerte esperanza de alcanzar mejores estados de cosas mediante el derecho constitucional; estos textos apuntan a metas maximalistas y al tratamiento estrictamente normativo de los derechos en general y de los derechos sociales en particular; los textos aspiracionales entienden la constitución como cartas de navegación que, reconociendo una distancia muy grande entre lo que existe y lo deseable, pretenden situarse en el centro de fuertes dinámicas de cambio. ${ }^{34}$

Cádiz fue claramente una constitución imbuida de filosofía aspiracional. No estaba diseñada para entorpecer el cambio abrupto, sino para provocarlo. Su corta vigencia - o las dificultades que se documen-

${ }^{33}$ Véase Saffon y García Villegas, op. cit., pp. 75-107, y García Villegas, "El derecho como esperanza: constitucionalismo y cambio social en América Latina, con algunas ilustraciones a partir de Colombia”, en García Villegas, Rodrigo Uprimny y César Rodríguez, ¿Justicia para todos?, 2006, Bogotá, Norma.

${ }^{34}$ Ibid., p. 79. 
taron en América, por ejemplo, para empezar a aplicar la libertad de imprenta y que dieron argumentos a los virreyes para proceder a su suspensión $-{ }^{35}$ muestra qué lejos estaban las proclamas gaditanas del status quo sobre el que deseaba proyectar su fuerza normativa, y el hecho mismo de desear plasmar, en el máximo detalle, tantos aspectos de la estructuración orgánica y procedimental de un nuevo orden es igualmente demostrativo de su voluntad (y necesidad) de crear nuevas realidades desde el derecho.

Los textos que hacen parte del nuevo constitucionalismo latinoamericano $^{36}$ tienen en este punto una continuidad absoluta con Cádiz: señalan oficialmente lo deseable, no lo existente. Con todo y separarse mucho del modelo regional estándar, la constitución mexicana -tanto en sus partes detalladas como en las abstractas, tanto en las antiguas como en las modernas- muestra igualmente el trazo de un país que no existe: "toda persona tiene derecho a decidir de manera libre, responsable e informada sobre el número y el espaciamiento de sus hijos"; "toda persona tiene derecho a la alimentación nutritiva, suficiente y de calidad. El Estado lo garantizará"; "toda persona tiene derecho al trabajo digno y socialmente útil".

Lo crucial es entender que esto es así, tomar conocimiento de la experiencia de otros países de la región con constituciones del mismo estilo en contextos socio-económicos no muy distintos. Las constituciones aspiracionales no se autocumplen y el progreso en su ejecución depende de que se vaya dando una cierta complementariedad entre acción política, social y jurídica. Como ha sido destacado para el caso colombiano, la voluntad política de los agentes estatales, la movilización social de la población y el cultivo de una cultura jurídica que favorezca la protección de los derechos, son fundamentales para que estas constituciones se materialicen y produzcan cambio social

${ }^{35}$ Véase Silvio Zavala, "La Constitución política de Cádiz, 1812. Marco histórico", en Patricia Galeana, op. cit., p. 22.

${ }^{36}$ Véase Rodrigo Uprimny, "Las transformaciones constitucionales recientes en América Latina. Tendencias y desafíos", en César Rodríguez Garavito (coord.), El derecho en América Latina: los retos del siglo XXI, 2011, Buenos Aires, Editorial Siglo XXI. 
efectivo. ${ }^{37}$ Dado que las metas ambiciosas forman parte esencial de este tipo de constituciones - a diferencia de lo que ocurre con las de conservación-, el desarrollo legal y jurisprudencial, destacan Saffon y GarcíaVillegas, es imprescindible, pero no suficiente en cualquier caso, para su aplicación efectiva, pues los agentes estatales centralmente encargados de aplicar sus mandatos deben ser apoyados y estimulados por la acción ciudadana. ${ }^{38} \mathrm{Si}$ no, los derechos y objetivos constitucionales pueden acabar siendo meramente simbólicos o, peor, temporalmente desmovilizadores -si es que consiguen crear la ilusión de que las proclamas constitucionales de algún modo existen-, para quizá transformarse, finalmente, en elementos deslegitimadores de la constitución, si la gente llegara a entenderlos como una especie de "estafa".

Los cambios económicos, sociales y políticos que el mundo ha experimentado de Cádiz a esta parte sugieren que comprometerse con el proyecto constitucional en América Latina requiere impulsar un proyecto necesariamente distinto al liberalismo decimonónico. Aunque el liberalismo sigue siendo necesario -porque en muchos ámbitos sigue siendo un proyecto inconcluso-, para hacer realidad las promesas de nuestras normas más altas en contextos en que las fuentes de poder potencialmente amenazantes son tanto o más privadas que públicas, en que los incumplimientos constitucionales derivan frecuentemente de omisión, no de acciones, o en los que las relaciones entre poderes son muy distintas a las presupuestas por los diseños institucionales fundacionales, deben usarse técnicas jurídicas e instrumentos de política pública muy distintas a las del constitucionalismo liberal clásico.

\section{Conclusión}

Dedicar un tiempo a buscar y analizar continuidades entre la Constitución de Cádiz y la Constitución mexicana actual, en un contexto histórico en el que uno esperaría encontrar menos, me parece un ejercicio útil para captar de mejor modo cómo es nuestra vida bajo la Constitución.

${ }^{37}$ Saffon y García-Villegas, op.cit., p. 80.

${ }^{38}$ Ibid., pp. 80-1 
Lo que no queda claro es que arroje un resultado tranquilizador. Contemplar la Constitución actual -como texto, como diseño, como arquitectura-desde Cádiz y tomando en consideración lo que implica que hayan pasado doscientos años, pone de relieve muchos de sus elementos subóptimos: es demasiado abigarrada, demasiado detallada y, además, demasiado heterogénea; es producto de la acumulación de momentos históricos muy distintos, más que de una síntesis, y algunas de sus características más notorias hacen de su administración cotidiana una empresa muy compleja. Pero por encima de todo, adoptar esta perspectiva quizá nos ayuda a reflexionar en torno a las fuentes de las dificultades que enfrentamos para pasar - por decirlo en palabras de Josep Aguiló- de "tener una Constitución" a "vivir en Constitución". 39

A mi juicio, el ejercicio es además necesario para ser fieles a la razón por la cual Cádiz se ha convertido en un mito con una buena función -y con efectos razonablemente buenos-: la voluntad de ser una carta de navegación que ayude a construir con la ayuda del derecho, y desde o con el derecho, una sociedad distinta a la que tenemos: una sociedad más justa. Pero exige entonces, como he sostenido al final de la sección anterior, entender a qué respondía el gran proyecto liberal de Cádiz y ser capaces de trabajar, en realidad, por un entendimiento y una administración pos-liberal de nuestra Constitución.

${ }^{39}$ Aguiló Regla, op.cit., pp. 42-3. 
CITAM Derechos Reservados.

La reproducción total o parcial de este artículo se podrá hacer si el ITAM otorga la autorización previamente por escrito. 